\title{
FUNCTION IMPACT MATRIX FOR SUSTAINABLE CONCEPT GENERATION: A DESIGNER'S PERSPECTIVE
}

\author{
William Z. Bernstein, Devarajan Ramanujan, \\ Srikanth Devanathan \\ School of Mechanical Engineering \\ Purdue University \\ West Lafayette, IN, USA
}

\author{
Fu Zhao ${ }^{12}$, John Sutherland ${ }^{2}$, Karthik Ramani ${ }^{1}$ \\ ${ }^{1}$ School of Mechanical Engineering \& ${ }^{2}$ Division of \\ Environmental and Ecological Engineering \\ Purdue University \\ West Lafayette, IN, USA
}

\begin{abstract}
Reducing the environmental effects of products has become a significant focus of corporate strategies. As a result, easy-to-use ecodesign tools that can be implemented during the early design stage are essential for corporations to gain a competitive advantage in product development. A novel ecodesign method, the function impact matrix (FIM), is being developed as a tool to enable the development and evaluation of design concepts by correlating environmental impacts with product functions. This paper aims to illustrate the efficacy and relative ease of use of the FIM. Understanding designers' interactions with visual tools and cognitive load analysis of designers can provide new insight that aids in the development of easy-to-use ecodesign tools. In this research, design engineers with varying levels of experience and self-perceived eco-design knowledge are asked to redesign an alarm clock under four different design scenarios: 1) using no eco-design tools, 2) using the LiDS wheel and an ecodesign checklist, 3) raw life cycle assessment (LCA) data and 4) the function impact matrix. Surveying the designers reveals that the function impact method carried the highest overall rank compared to the other ecodesign tools with regard to ease of use, quality of data, ability for identifying redesign opportunities, and overall effectiveness. As suggested by the designers, a combination of a modified LiDS wheel with the FIM would lead to a helpful tool for sustainable concept generation.
\end{abstract}

\section{INTRODUCTION}

This paper aims to illustrate the efficacy and ease of use of a novel eco-design tool, the Function Impact Matrix (FIM) which was recently developed to correlate environmental impacts with product functions and reveal opportunities for sustainable concept design [1]. According to the National Academy of Engineering, achieving an environmentally sustainable society is one of today's greatest challenges [2]. Consumer compliance to limit one's individual carbon footprint has never been higher. Therefore, reducing the environmental effects of products has become an important focus for corporate environmental strategies [3]. Additionally, anticipated environmental policy changes are pressuring industry to adopt an environmentally conscious attitude towards product development [4]. Product design, though amounting for only $5 \%$ of the entire cost of a product, commits about $70 \%$ of the entire project cost [5]. Correspondingly, we can hypothesize the same to be the case for environmental impacts. That is, whether or not a product is relatively sustainable is largely determined during the design stage.

Similar to traditional design tools, structured presentation and intuitive visualization are key components for developing an effective ecodesign aid. Cognitive studies of designers reveal that design parameters must be presented in a structured manner for the designer to succeed. This issue is highlighted in the case of novice designers, who tend to overlook the complex dynamic relationships between design parameters [6]. Moreover, as pointed out by Hwang and Ullman, 1990, simply the visualization of design factors and parameters decreases the designer's cognitive load. This creates a congenial design environment that fosters innovation [7]. Therefore, there is a need for incorporating sustainability at the early design stage of the product realization, especially in the form of visual design aids.

Eco-design tools have been developed in the past to assist engineers in understanding environmental sustainability at the design phase. These tools fall under three main 
categories: (1) eco-checklists, (2) QFD-based tools and (3) LCA-based tools [8]. The following paragraphs present a brief overview of these tools for their suitability as effective ecodesign visual aids at the concept development stage.

Eco-checklists: Such checklists question decisions made by the designer and aim to guide him towards the creation of a sustainable design concept. These qualitative tools frame bimodal questions to designers regarding the product's lifecycle. Although an excellent starting point to raise environmental awareness, checklists are limited by their generality and rarely engage designers in the innovative thought processes that may lead to new product opportunities. Though the proper use of these tools requires the user to have extensive experiences and knowledge pertaining to sustainability, eco-checklists have gained considerable penetration into industrial practices, especially within small and medium size companies [9]. Checklist items include, for example, "is less energy consumed during the use phase of the product than the existing ones?" or "are less toxic materials used in the product?" [10]. These tools are developed particularly for the early stages of the product development process. Compared with LCA-based tools, these tools are much more subjective. When trade-offs exist between different life cycle stages or different environment impacts categories, checklists can rarely offer concrete solutions [11].

QFD-based tools: Unlike eco-checklists, QFD-based ecodesign tools attempts to incorporate objectivity into ecodesign. This is achieved by introducing environmental impacts of the product itself and over its life cycle into QFD's as new customer needs. Common QFD-based ecodesign tools include Quality Function Deployment for the Environment, Green Quality Function Deployment, and the House of Ecology $[12,13]$. In general, application of these tools starts from collecting both customer needs and environmental needs, and developing correlations between these needs and quality characteristics. A functional analysis is then performed to identify how quality characteristics are correlated with engineering characteristics (including structure or components). Design "hot spots" from both environmental as well as from a performance point of view can be revealed. One serious limitation of these QFD based tools is that the development of correlations between environmental needs and quality and engineering characteristics is completely reliant on designers [14]. Usually, the correlations developed are based on knowledge from traditional environmental engineering discipline without the consideration of the product's entire life cycle. Similar to checklists, QFD-based tools can rarely offer concrete solutions.

LCA-based Tools: Life Cycle Assessment (LCA) tools have been developed to identify environmental consequences of a product or process throughout each of its life cycle stages. Standardized by the ISO in 1997 and updated in $2006[15,16]$, LCA provides a thorough analysis of a product and, compared to the pre-mentioned tools, provides the most accurate estimation of a product's environmental footprint. Because of the high levels of uncertainty and lack of data during the early design stages, LCA, in its current form, is not design-oriented can be very costly and time prohibitive, which especially affects smaller companies. [17]. Streamlined LCA methods have been proposed but these methods tend to ignore environmental impacts from certain life cycle stages, material/energy flows and impact categories [18,19]. The LCA based tools, however, do not provide a visual interface to designers, and thus have gained little acceptance with regards to the product design process.

Many organizations prefer simpler visual ecodesign tools such as the life cycle design strategy (LiDS) wheel. This ecodesign tool maps the entire product life cycle by dividing it into eight categories: (0) new concept development (1) low impact materials (2) dematerialization (3) cleaner production (4) distribution (5) use phase impact (6) initial lifetime (7) end of life logistics [20]. This qualitative tool has been widely recognized as a useful tool for sustainable product realization. Similar to the eco-checklists, results from the LiDS wheel are highly dependent on the designer's intuition and experiences.

Current ecodesign tools, due to low levels of data transparency, amplify the designer's preconceived notions of sustainability [21]. Media outlets, public misconceptions, and organizational culture all provide misinformation about what "sustainability" means. The gap between understanding the environmental impacts associated with material preparation and processing as well as supply chain and end-of-life logistics has forced designers to make uneducated decisions about sustainability. For example, in the late twentieth century, there was a far-reaching sentiment that metal is more environmentally benign than plastic. Media sources have continuously cited the "hazardous chemicals" required to form certain types of plastic but have neglected to investigate the resource and energy requirements to mine and smelt metals. This example is simply a microcosm of arguably the biggest hurdle in creating an environmentally sustainable future, 'greenwashing'. Greenwashing is defined as "the selective disclosure of positive information about a company's environmental performance, without full disclosure of negative information on these dimensions" [22]. For widespread acceptance and popularity of an ecodesign tool, it should require minimal background knowledge of sustainability and also be quick and easy to interpret and use. To truly integrate effective ecodesign tools, a combination of education and training, as well as appropriate presentation and easy access are critical for their success [23]. However, to be truly effective the tool must shade the designer's perspective from these sources of misinformation. Therefore, incorporation of objective data (i.e. from LCA) into easy-to-use ecodesign tools is essential [24].

\section{FIM BASED METHOD}

In the author's previous work, the function impact matrix (FIM) has been presented as a novel ecodesign methodology that facilitates the use of life cycle assessment (LCA) data to support the visualization during the early design phase. The FIM distributes the life cycle environmental impacts across 
product functions. The main goal of the FIM is to identify the environmental impact of each function with respect to the overall system performance, as well as to reveal potential areas for re-design [1]. The mathematical representation of environmental impacts attributed to each function is given in Equation 1:

$$
\text { (1) } \mathrm{FI}=\left[\beta_{i, j, n}\right]=\left[\left\{\sum_{k}\left(M_{i, j, k}+\sum_{m} P_{i, j, k, m}\right) \cdot \alpha_{k, n}\right\}+U_{i, j} \cdot \gamma_{n}\right]
$$

where $\beta_{i, j, n}$ is environmental impact of category $j$ due to function $n$ for benchmark product $i$, and $\gamma_{n}$ is the percentage of function $n$ contributes to the overall functionality (i.e. the use) of the product. Furthermore, $M_{i, j, k}$ is the environmental impact category $j$ associated with component $k$ due to material. $P_{i, j, k, m}$ is the environmental impact of category $j$ associated with component $k$ due to the $m$-th manufacturing step, and $U_{i, j}$ is the environmental impact of category $j$ during the use of the product. For example, if a product included a motor to perform a specific function, the environmental impact associated with powering the motor would carry some percentage $\left(\gamma_{n}\right)$ of the total impact during the product's use phase. In general, $\gamma_{n}$ allows the designer to trace functions back to a component level from a use phase perspective, while $\alpha_{k, n}$ indicates the percentage distribution of each component to a given function during all other significant phases of a product's life cycle.

In the authors' previous work, the FIM was implemented towards a stapler re-design case study and the results therein were promising [1]. However, past work was performed by ecodesign experts, not common engineering designers. Thus, it is essential to explore the perspective of the common designer to assess if FIM is cognitively effective.

Within this study, by interviewing designers, challenges to achieve sustainable product realization are recognized. Assessing each designer's attitudes and opinions reveal specific reasons why ecodesign tools have not gained widespread acceptance in industrial practices. This insight will help in the development of FIM and other related eco-design tools to provide a framework for sustainable product development.

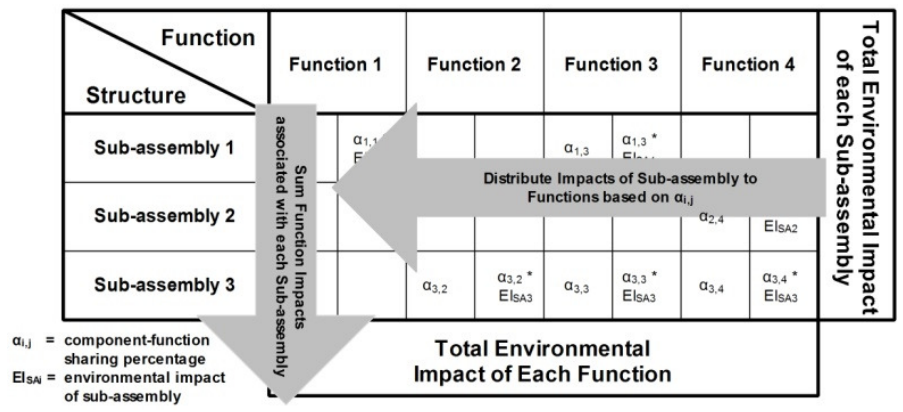

Figure 1: Matrix representation of the function impact method

\section{METHODOLOGY}

To illustrate the usefulness of the FIM, designers with varying levels of design experience, and self-perceived ecodesign knowledge were selected for design interviews. Before each interview, the designers were asked to provide a score of their prior eco-design knowledge on a scale 1-10, where " 1 " implies extremely limited knowledge and " 10 " reflects a high level of expertise. The designers were asked to provide a redesign solution concerning two generations of a portable alarm clock. (1) A wind-up mechanical alarm clock in which a torsion spring stores and releases energy to rotate gears that regulate time. The mechanism for the alarm consists of an additional torsion spring, which upon unwinding oscillates a hammer that strikes a bell at a pre-set time. (2) A battery powered electronic alarm clock with an LCD display which uses a printed circuit board to keep time and sound an alarm. This clock is powered by a single AA battery. Product teardown was first performed and a bill of materials was constructed for each clock. The bill of materials (BOM) included: part weight, type of material, part quantity, a photograph and a brief description of its function. Materials and manufacturing processes were interpolated for each component with the help of experts. A life cycle assessment (LCA) was performed using SimaPro 7.1 with the Ecoinvent 2.0 database for each part. Transportation emissions were not considered since compared with material extraction and manufacturing stages, the environmental impact from transportation was negligible. End of life logistics and other supply chain issues were beyond the scope of the study.

To avoid any instances where elements of the design solution were possibly influenced by the interviewers, designers were provided with a printed copy of the problem definition along with instructions outlining each of the following design scenarios: (1) a problem definition along with the BOM containing no LCA data, (2) a modified LiDS wheel comparing the clock designs, generated from actual LCA data and an ecodesign checklist, (3) a visual representation of the environmental impacts from the LCA of each of the clocks' components, and (4) visual representations of the function impact method. The designers were limited to the design space of the two generations of alarm clocks. For example, to achieve the function of powering the clock, no other energy sources could be used besides the action of winding spring steel or including a battery source. Explanation of any eco-design tools was provided by the interviewers if needed. This included a background of the derivation of an eco-indicator single score obtained from the Ecoinvent 2.0 database. The designers were asked similar questions after each design scenario regarding their re-design and respective attitudes towards each design tool, including degree of relevance, ease of application, and ease of visualization. Designers were also asked to rank the tools based on which one revealed opportunities for innovation.

It should be noted the LiDS wheel was completed before the interview based on actual LCA data. Traditionally, the LiDS wheel is used by designers to qualitatively asses a product's environmental soundness with regards to eight stages of its life cycle. However, in this study, a modified LiDS wheel with actual quantitative information was used to assess the need for visual representation of LCA data during design. Each interview lasted for about an hour and was recorded via both video and audio. 


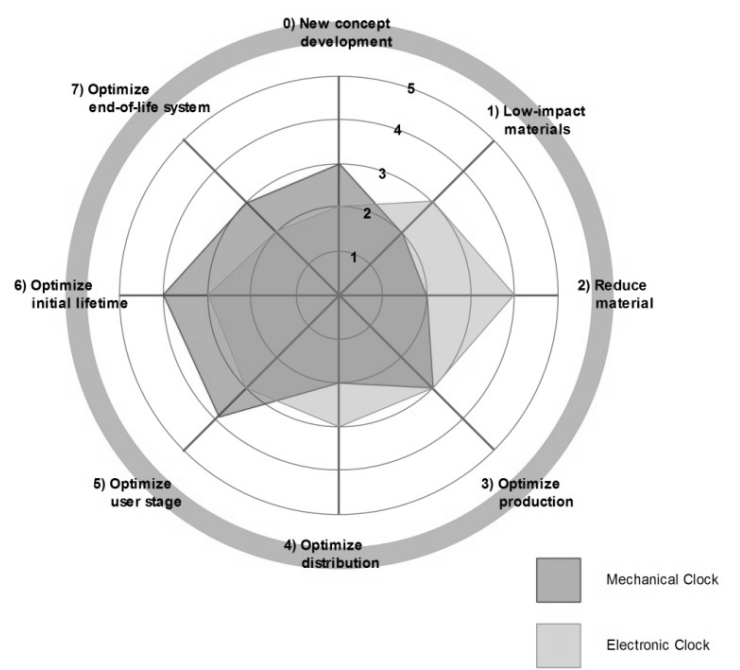

Figure 2: LiDS wheel for both alarm clock designs

Along with the modified LiDS wheel, the designers were provided with an ecodesign checklist to assess their redesign. Table 1 illustrates the categories of the provide checklist along with a sample items from each section. The designers were required to provided data either in form of bimodal answers and/or brief explanations. A description of the redesign methodology adopted by the designer during subsequent stages follows.

Table 1: Sample ecodesign checklist [25]

\begin{tabular}{l|l}
\hline Category & Sample Checklist Item \\
\hline Material & $\begin{array}{l}\text { Product contains renewable materials. Yes } \square \text { No } \square \\
\text { Product contains recycled materials. Yes } \square \text { No } \square \\
\text { Materials use has been minimized. Yes } \square \text { No } \square\end{array}$ \\
\hline Emissions & $\begin{array}{l}\text { Product contains no VOC's or CFC's. Yes } \square \text { No } \square \\
\text { Chemical emissions have been minimized. Yes } \square \text { No } \square\end{array}$ \\
\hline Energy & $\begin{array}{l}\text { List sources of energy used in the product: } \\
\text { Energy consumption info is available. Yes } \square \text { No } \square \\
\\
\text { Product is energy-star compliant. Yes } \square \text { No } \square\end{array}$ \\
\hline Consumables & Design has min. amount of consumables. Yes $\square$ No $\square$ \\
\hline Packaging & $\begin{array}{l}\text { Packaging materials is reduced. Yes } \square \text { No } \square \\
\text { Recycled packaging materials are used. Yes } \square \text { No } \square\end{array}$ \\
\hline End-of-Life & $\begin{array}{l}\text { Materials can be easily separated. Yes } \square \text { No } \square \\
\text { Plastic recycling no's are clearly indicated. Yes } \square \text { No } \square\end{array}$ \\
\hline Product Life & $\begin{array}{l}\text { Product contains modular components. Yes } \square \text { No } \square \\
\text { Product contains standardized parts. Yes } \square \text { No } \square\end{array}$ \\
\hline Hazardous Subs. & $\begin{array}{l}\text { Product is WEEE and RoHS compliant. Yes } \square \text { No } \square \\
\text { No parts contribute to hazardous waste. Yes } \square \text { No } \square\end{array}$ \\
\hline Life Cycle Aspects & $\begin{array}{l}\text { No stage has adverse ecological effects. Yes } \square \text { No } \square \\
\text { All departments comply with eco-policies. Yes } \square \text { No } \square\end{array}$ \\
\hline Misc. & $\begin{array}{l}\text { Product benchmarking has been done. Yes } \square \text { No } \square \\
\text { Product's eco-attributes are available. Yes } \square \text { No } \square\end{array}$ \\
\hline
\end{tabular}

\section{RESULTS AND DISCUSSION}

The design scenarios were ordered in such a manner that every subsequent stage provided additional information regarding sustainability. Thereby, each redesign scenario added to the designers existing eco-knowledge and provided an opportunity for refining their redesign. The designers had extensive experience in mechanical design but lacked exposure to ecodesign methodologies.

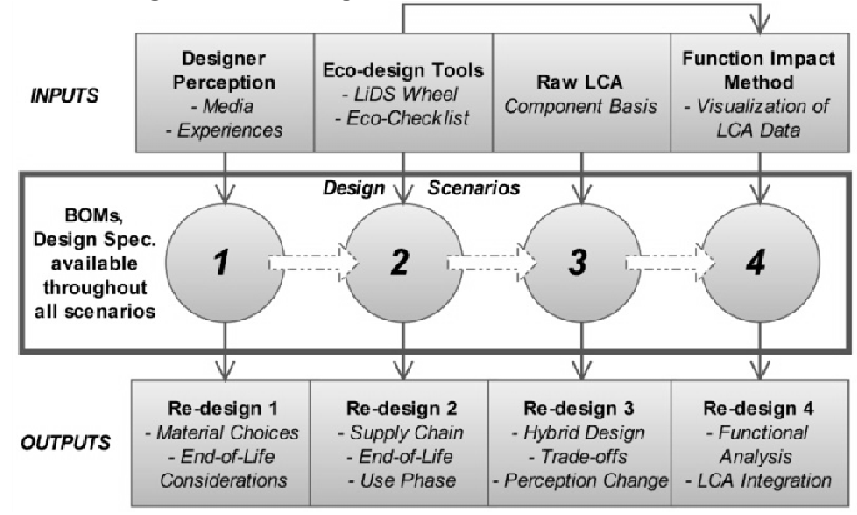

Figure 3: Summary of the design experiment with results

Scenario (1). With no formal introduction to the concepts of environmental sustainability, the methodology for redesign for sustainability was entirely a result of the designer's experience and perception of ecodesign. For the designer, sustainability at this stage simply equated to the product's endof-life scenario. Therefore, all the choices made were an effort to mitigate the impact of product disposal, and thus, focused on material choices. The designers had a notion that metal in general is more sustainable than plastic. Therefore they chose the mechanical alarm clock as their baseline for the redesign. Efforts were directed towards incorporating more recycled and re-useable items. Designers cited the ability to melt down used metal parts for remanufacturing and reuse. As a result, the redesign solution was centered on incorporating additional metal-based components. The important observation made during this stage is that designers do not recognize the environmental impacts of every life cycle stage (i.e production, distribution, etc.).

Scenario (2). When introduced to the formal definition of sustainability (as coined by the Brundtland Commission 1997 [26]) and ecodesign tools such as the LiDS wheel and an ecodesign checklist, a marked improvement in the design strategy is visible. The LiDS wheel particularly helps the designer methodically assess each stage of the product lifecycle from an environmental standpoint. The designers started addressing the concerns of each of the stages. Typical inferences drawn from the use of LiDS wheel include: (a) the energy for mining and processing metal in general is higher than plastics and therefore it may not be more sustainable and (b) the need to reduce product dimensions, in order to minimize environmental impacts of transportation and packaging. There was general agreement regarding the ease of use of the ecodesign checklist. However, the designers strongly felt that the content was highly subjective and general. The overarching conclusion was that the LiDS wheel opens new opportunities for ecodesign by virtue of a stage by stage approach and the eco-checklist serves as a final check to meet the required constraints. Both these tools helped the designers approach the concept of ecodesign with a scientific basis, but were too 
general to offer any concrete solutions. Therefore, the designers stood by their original baseline for redesign albeit a few modifications to reduce the environmental impacts in the downstream stages of the lifecycle. An interesting trend observed at this stage is that the designer tends to redesign based on design for manufacturing (DFM) guidelines [27]. For example, some of the modifications proposed were the following: eliminating fasteners, minimizing overall weight, minimizing number of parts, and reducing number of manufacturing operations. Since the tools at this stage are still general, designers' perceptions have a significant bearing on the design solution. Interestingly, this potentially amplifies misconceptions regarding sustainability issues. This is evident specifically in end-of-life considerations. For example, the designers shared the viewpoint that difficulties in remanufacturing plastic components offset their advantages in resource use compared with metals. The eco-checklist and LiDS wheel do nothing to refute these claims due to lack of quantitative data. In other words, designers cannot use their own intuition to overhaul their perceptions using these tools.

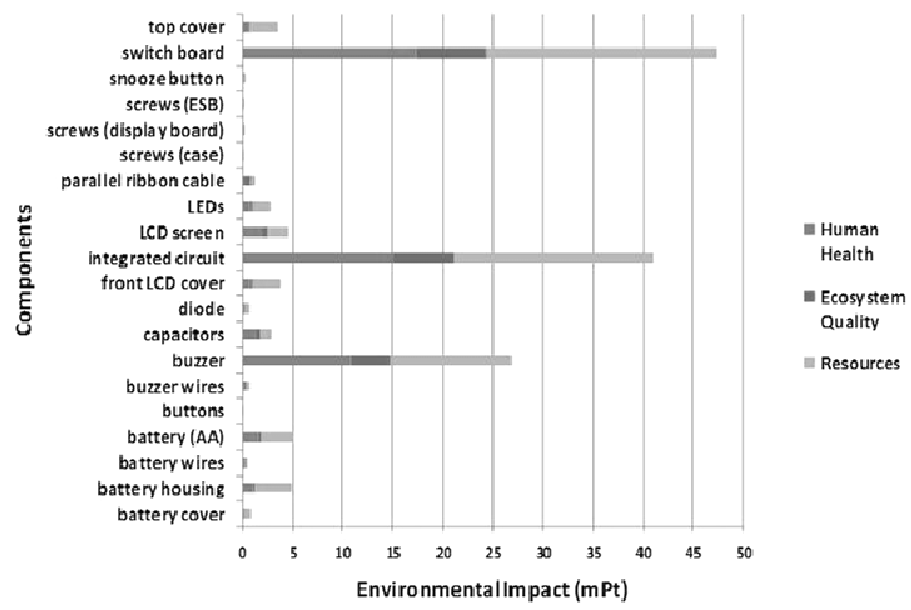

Figure 4: Visual representation of raw LCA data for the electronic alarm clock

Scenario (3). Next, the designers were provided with visual representations of raw data from the life cycle assessment conducted using SimaPro 7.1 and a brief explanation of category indicators. The data came as a surprise as the results were against their intuition that the mechanical alarm clock is more sustainable than the electronic version. By quantifying environmental impacts, the life cycle assessment data presented an opportunity for comparing parts and sub assemblies that make up a design. Therefore, the designers adopted the strategy of constructing a hybrid design by combining parts which have the least environmental impact. For example, for producing sound, an electronic enunciator was chosen over the hammer and bell mechanism. Moreover, the gear train was preferred over the electronic switch board for the function of 'regulating time'. Though this may seem straightforward, creating a hybrid design is complex as in any design the components cannot function independent of one another. Therefore, use of the electronic enunciator inherently implies that an electronic switchboard will also be required, increasing the environmental impact of the system. Such trade offs were recognized by the designers. This, coupled with the explosion of data made it difficult to conceptualize a design.

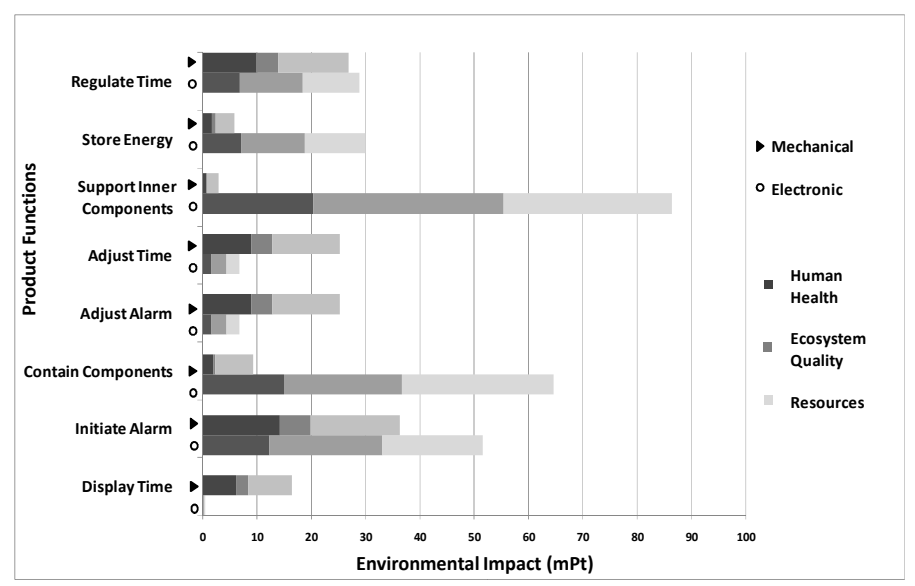

Figure 5: Function impact chart for both alarm clock designs

Scenario (4). Finally, the designers were given an introduction to the function impact method. This included the function impact matrices, and their visual counterparts. The designers could immediately identify primary and secondary functions. As a result, the designers adopted a strategy of modifying the secondary functions that had significantly high environmental impacts. The key point to be noted is that although the electronic clock had a lesser environmental impact when compared to the mechanical clock, the impacts of primary function did not follow the same trend. Therefore, there was limited scope for redesigning the electronic design for sustainability. On the other hand, the environmental impact of the mechanical clock resulted largely from its secondary functions. Hence, it was possible to easily use the mechanical clock as a baseline and conceive a far more sustainable product concept. As hypothesized, the designers chose the mechanical clock as their baseline for redesign and moved towards a hybrid design.

Table 2: Designer's ranking of ecodesign tools

\begin{tabular}{ccccc}
\hline $\begin{array}{c}\text { Design } \\
\text { Scenario }\end{array}$ & $\begin{array}{c}\text { Ease of } \\
\text { use }\end{array}$ & $\begin{array}{c}\text { Data } \\
\text { quality }\end{array}$ & $\begin{array}{c}\text { Ability to identify novel } \\
\text { redesign opportunities }\end{array}$ & $\begin{array}{c}\text { Overall } \\
\text { Ranks }\end{array}$ \\
\hline $\begin{array}{c}\text { LiDS Wheel } \\
\text { Ecodesign }\end{array}$ & $\mathbf{3}$ & $\mathbf{3}$ & $\mathbf{2}$ & $\mathbf{2}$ \\
Checklist & $\mathbf{1}$ & $\mathbf{4}$ & $\mathbf{4}$ & $\mathbf{4}$ \\
Raw LCA Data & $\mathbf{4}$ & $\mathbf{1}$ & $\mathbf{3}$ & $\mathbf{3}$ \\
FIM & $\mathbf{2}$ & $\mathbf{2}$ & $\mathbf{1}$ & $\mathbf{1}$ \\
\hline & & \multicolumn{3}{c}{ rank: 1 = most preferred, 4=least preferred }
\end{tabular}

After the four design scenarios, the designers were asked to rank all design tools based on four criteria: (1) ease of use, (2) quality of data, (3) ability for identifying redesign opportunities, and (4) overall effectiveness. The function impact method carried the highest overall rank compared to the other ecodesign tools. Furthermore, designers consistently cited that some combination of LiDS wheel with the FIM 
would be the most helpful in a design scenario. This is because the LiDS wheel provided a holistic overview of every life cycle stage, which enabled the designers to methodically focus on every aspect of the re-design. But, without function-oriented thinking, they did not have access to quantitative data to support their decision making. This confirms the need for visual representations of quantitative LCA data to promote sustainable product realization.

\section{CONCLUSIONS}

Because technical design involves high cognitive load due to multi-attribute analysis encompassing various physical disciplines, it is essential to frame quantitative data in a visual form [28]. Without data projection to the early design phase, perception developed from media outlets and past experiences drive decisions to satisfy eco-requirements. Therefore, to achieve sustainable product development, designers must have access to meaningful visual representations of real LCA data. The function impact method allows designers to evaluate primary and secondary functions of design embodiments from an environmental perspective. The FIM thus reveals innovative product redesign opportunities. From a designer's perspective, the function impact method provides an easy-to-use visual interface for LCA data that enables ecodesign via a scientific basis. Future research will involve analysis of a larger designer population with various levels of eco-experience, as well as quantification of each redesign scenario from an environmental perspective. The authors will also continue developing FIM into a fully holistic tool that addresses all life cycle stages.

\section{ACKNOWLEDGMENTS}

The work is partially supported by NSF under grant EEC0935074. This paper does not necessarily reflect the view or opinions of the agency. We also thank the support of the Division of Environmental and Ecological Engineering at Purdue University.

\section{REFERENCES}

[1] Devanathan, S., 2010. "Integration of sustainability into early design through working knowledge model and visual tools", Journal of Mechanical Design. Submitted January 2010.

[2] National Academy Of Engineering, 2008. "Grand Challenges For Engineering."

[3] Boons, F., 2002. "Greening product: a framework for product chain management." Journal of Cleaner Production. 10 pp. 495-505.

[4] Earnhart, D. H., et al., 2000. "Final Report: Shaping Corporate Environmental Behavior and Performance: The Impact of Enforcement and Non-Enforcement Tools", Corporate Environmental Performance and the Effectiveness of Government Interventions.

[5] Ullman, D. G., 2003. The Mechanical Design Process. McGraw-Hill Publishing Company.
[6] Mathias, J. R., 1993. "A study of the problem solving strategies used by expert and novice designers", $P h D$ Thesis, University of Aston. Birmingham, UK.

[7] Hwang, T.S., Ullman D. G., 1990. "The design capture system: capturing back-of-the-envelope sketches", Journal of Engineering Design.

[8] UNEP, 2005. "Life Cycle Approaches: The Road from Analysis to Practice", A UNEP/ SETAC Life Cycle Initiative Report.

[9] Luttropp, C., Lagerstedt, J., 2006. "EcoDesign and the Ten Golden Rules: Generic Advice for Merging Environmental Aspects into Product Development", Journal of Cleaner Production, Vol.14, pp.1396-1408.

[10] Lee, K.M., Park, P.J., 2005. "EcoDesign: Best Practice of ISO-14062", Eco-product Research Institute (ERI), Ajou University, Korea.

[11] Eisenhard, J. L., et. al. 2000. “Approximate life-cycle assessment in conceptual product design", ASME 2000 DETC.

[12] Masui, K., Sakao, T., Kobayashi, M., Inaba, A., 2003. "Applying Quality Function Deployment to Environmentally Consious Design", International Journal of Quality and Reliability Management, Vol.20, pp.90-106.

[13] Sakao, T., 2007. “A QFD-centred Design Methodology for Environmentally Conscious Product Design”, International Journal of Production Research, Vol.45, pp.4143-4162.

[14] Dikmen, I, Bigonul M. T., Kiziltas S., 2005. "Strategic use of quality function deployment (QFD) in the construction industry", Building and Environment. Vol. 40 No. 2.

[15] International Standard Organization (ISO), 1997. Environmental management - Life cycle assessment Principles and framework. ISO 14040, June 1997

[16] International Standard Organization (ISO) 2006. ISO 14044: environmental management-life cycle assessment-requirements and guidelines.

[17] Hoffmann, V. H., McRae, G.J. and Hungerbuhler K., 2004. "Methodology for early-stage technology assessment and decision making under uncertainty: application to the selection of chemical processes", Industrial \& Engineering Chemistry Research. 43 (15), pp. 4337-4349.

[18] Todd, J. A., Curran, M. A., 1999. "Streamlined LifeCycle Assessment: A Final Report from the SETAC North America Streamlined LCA Workgroup", Society of Environmental Toxicology and Chemistry (SETAC) and SETAC Foundation for Environmental Education.

[19] Koffler, C., Krinke, S., Schebek, L., Buchgeister, J., 2008. "Volkswagen slimLCI: A Procedure for Streamlined Inventory Modeling within Life Cycle Assessment of Vehicles", International Journal of Vehicle Design, Vol.46, pp.172-188.

[20] Brezet, H., Van Hemel, C., 1997. "Ecodesign: A promising approach to sustainable production and 
consumption", Rathenau Institute, TU Delft \& UNEP, Paris.

[21] Bovea, M.D., Gallardo, A., 2006. "The influence of impact assessment methods on materials selection for eco-design" Materials \& Design. (27) 3. Pp. 209-215.

[22] Lyon, T. P., Maxwell, J. W., 2006. "Greenwash: Corporate Environmental Disclosure under Threat of Audit," Working Papers 2006-07, Indiana University, Kelley School of Business, Department of Business Economics and Public Policy

[23] Lofthouse, V., 2006. "Ecodesign Tools for Designer: Defining the Requirements", Journal of Cleaner Production, Vol.14, pp.1386-1395.

[24] Ritzen, S., Lindahl M., 2001. "Selection and implementation - key activities to successful use of ecodesign tools", $2^{\text {nd }}$ International Symposium on Environmentally Conscious Design and Inverse Manufacturing (EcoDesign '01).

[25] European Computer Manufacturers Association (ECMA), 2008. Environmental Design Consideration for ICT \& CE Products. Standard ECMA-241 $3^{\text {rd Edition. }}$

[26] Brundtland. G.H., 1987. "Our Common Future". World Commission on Environment and Development. (Oxford University Press), Oxford, UK

[27] Dieter, G.E., 2000. Engineering design: a materials and processing approach. McGraw-Hill Science.

[28] Ashby M. F., Johnson K. W., 2001. "Classification and choice in product design". Cambridge Design Center. CUED/C-EDC/TR108 